\title{
Psicologia hospitalar. Teoria, aplicações e casos clínicos
}

\author{
Alexandre José Raad ${ }^{1}$
}

Baptista, M. N. \& Dias, R. R. (Orgs.). (2003). Psicologia hospitalar. Rio de Janeiro: Guanabara Koogan, 176 p.

Inicialmente, a saúde mental foi agrupada dentro das doenças morais por falta de conhecimento. No Brasil, apenas a partir do século XIX é que houve alguma preocupação em relação ao tema, e só a partir do século XX é que a medicina a contemplou como especialidade médica. Observa-se que uma das características comportamentais mais marcantes das pessoas portadoras dessas patologias é a exclusão do convívio social, uma vez que sofrem influências culturais do capitalismo pragmático em detrimento do ponto de vista humanístico, relegando à saúde mental os últimos lugares a serem pensados dentro da questão da saúde.

Psicologia hospitalar foi organizado por dois experientes docentes e com a colaboração de 11 profissionais ligados à área da saúde mental. Consta de 10 capítulos e foi prefaciado pelo psiquiatra Francisco B. Assumpção Jr., que comenta histórica e politicamente as vicissitudes da Saúde Mental no Brasil. O livro tem por objetivo disseminar conceitos e propostas, conciliar aspectos entre Psicologia e Psiquiatria, estabelecendo os serviços de ligação por meio da penetração dessas duas áreas dentro do hospital geral.

Habilmente, os autores destacam a importância do profissional da saúde mental de incorporar o aprendizado e o aprimoramento dos aspectos interpessoais da tarefa assistencial e o conhecimento dos fenômenos psicológicos que atuam nessa trama. Isso quer dizer que, além do suporte técnico, o psicólogo deve desenvolver a sensibilidade para conhecer a realidade do paciente, ouvir suas queixas e encontrar com ele estratégias facilitadoras para aceitação e compreensão da doença, e contribuir para a adaptação e modificação que porventura sejam necessárias para dar conta do seu problema.

Com o título $A$ psicologia da saúde no mundo e a pesquisa no contexto hospitalar, os autores fazem um paralelo entre investimentos nesta área no exterior e no Brasil, qualidade e quantidade de serviços oferecidos e, independentemente de toda a controvérsia sobre o assunto, posicionam-se de forma otimista apontando a pesquisa como primordial para alavancar o conhecimento dessa área em nosso país.

Enfermagem e obstetrícia é o título do segundo capítulo, no qual se evidencia a necessidade de uma visão biopsicossocial da mulher. $O$ capítulo aponta também para a importância do planejamento familiar, e para a necessidade de o psicólogo ter o conhecimento dos estágios constituintes desse planejamento, para que dessa forma se possa intervir e orientar a mulher, já que cada estágio tem características diferentes e riscos específicos. Não se pode esquecer de apontar que o atendimento psicológico deve se estender à família e à equipe de saúde que atende a paciente, atuando como um facilitador nas relações entre a equipe de saúde, a paciente e a sua família, contribuindo assim para que se possa prevenir e amenizar os riscos maternos e/ou fetais.

O terceiro capítulo fala da Atuação psicológica em Unidade de Terapia Intensiva Neonatal - UTI-Neo. Nele se faz uma caracterização do recém-nascido quanto a peso, idade gestacional, entre outros, discorrendo sobre a importância da interação mãe-bebê, apontando que intervenções adequadas no período neonatal favorecem essa vinculação. $\mathrm{O}$ autor ainda aponta para a necessidade de uma maior preocupação com as condições iniciais da relação mãe-bebê, o que poderia auxiliar, de maneira fundamental, na prevenção de distúrbios psicológicos futuros, evitando gastos volumosos em programas terciários de saúde para combater os transtornos e problemas de saúde mental já instalados.

Enfermaria de pediatria: avaliação e intervenção psicológica é o título do quarto capítulo, no qual são apresentadas considerações, aspectos teóricos e práticos sobre a Psicologia Hospitalar Pediátrica. Objetivou expor o modelo assistencial psicológico, apresentado pelos autores, de um trabalho em enfermaria de pediatria de um Hospital Geral-Escola.

Aids no contexto hospitalar: manejo psicológico é discutido no quinto capítulo. A autora inicia traçando um histórico do aparecimento da doença, citando aspectos e reações psicológicas diante das diferentes fases de evolução da doença. A autora transcreve as cinco fases do processo de adaptação e convivência com o HIV+ e AIDS, e aponta para as reações psicológicas diante das crenças em relação à AIDS. Quando fala sobre o Programa de Avaliação e Intervenção Psicológica Destinado ao Paciente Soropositivo e/ou com AIDS, é mostrado que o objetivo geral do atendimento psicológico é verificar a relação entre a sintomatologia psicológica e o quadro orgânico.

Ana Paula Ferrari Pregnolatto e Valéria Batista Menezes Agostinho assinam o sexto capítulo, intitulado O psicólogo na Unidade de Terapia Intensiva - Adulto, no qual traçam um panorama do atendimento psicológico em UTI-A. Segundo as autoras, o propósito do

${ }^{1}$ Endereço para correspondência:

E-mail: alex.raad@ig.com.br 
psicólogo nessa empreitada é avaliar o paciente nos âmbitos médicos/biológicos, sociais/culturais e psicológicos sem abrir mão das diversas variáveis ligadas ao paciente, como por exemplo, seus familiares e a própria equipe de saúde que o assiste. Muitas vezes o paciente encontra-se impossibilitado de fornecer dados em virtude da seu quadro clínico ou procedimento em curso, e o psicólogo teria o objetivo de servir como um mediador entre o paciente, a equipe, a instituição e seus familiares.

Psiquiatria de ligação e interconsulta psiquiátrica na infância e adolescência é o título do sétimo capítulo, cujo objetivo é definir e descrever o campo de atuação da Psiquiatria da Infância e Adolescência na Unidade de Pediatria Geral, seja ela em um sistema ambulatorial ou de internação. Para isso, os autores definem o papel e os princípios a serem seguidos pelo psiquiatra infantil na abordagem terapêutica de pacientes psiquiátricos, relatam os dados de uma pesquisa sobre avaliação e os principais motivos da interconsulta de uma amostra hospitalar.

No oitavo capítulo, intitulado Ambulatório especializado no atendimento de crianças autistas, os autores iniciam traçando a história do autismo infantil a partir do século XIX. Engendram pelas classificações diagnósticas, servindo-se do CID-9 e CID-10, mostrando as patologias mais comumente associadas ao diagnóstico de autismo infantil. Apontam ainda características gerais de um Núcleo de Autismo Infantil, relatam um caso clínico, falam da importância do diagnóstico precoce da necessidade da diversidade profissional para permitir uma discussão mais abrangente e concluem apontando que o núcleo do autismo infantil cumpre seu papel assistencial ao atender crianças com transtornos invasivos do desenvolvimento.

O penúltimo capítulo, Sistema familiar de crianças com transtorno global do desenvolvimento, descreve os determinantes psicológicos de famílias com crianças com esse tipo de transtorno, especificamente autismo e esquizofrenia infantis. Inicia dizendo que o contexto familiar abordado nesse capítulo está de acordo com os pressupostos do pensamento sistêmico, em que o comportamento de um indivíduo do sistema afetará todas as partes e vice-versa. A autora define as crianças com transtorno global do desenvolvimento em relação aos comportamentos que governam e estabelecem os padrões familiares.

Preocupado com a Humanização em ambientes médicos, o autor Makilim Nunes Baptista, assessorandose de três colaboradores, escreve o décimo e último capítulo desta obra. Tecendo comentários a respeito da subjetividade do termo humanização, relatam que muitos fatores envolvem tal questão. Entretanto, é necessária a compreensão da realidade para se propor qualquer estratégia de humanização. Falam ainda da dificuldade de exatidão do termo, apontando exemplos para justificar tal afirmação. Este capítulo expõe uma pesquisa de levantamento realizada em uma UTI-A, de um Hospital-Escola, conveniada ao SUS, expondo os principais resultados quanto ao entendimento de diversos profissionais de saúde sobre o termo humanização.

É notória a excelente organização do livro. Os autores apresentam textos de fácil leitura e compreensão, não sem tratar dos assuntos com a profundidade apropriada para o objetivo da obra. Além disso, apresentam citações das pesquisas de maior repercussão quanto aos diversos temas tratados, localizando suas fontes e abrindo oportunidade para aprofundamento dos temas discutidos. Conforme sabiamente prefaciado por Francisco Assumpção Jr., apesar de saberem que estão na contramão dos interesses financeiros, não se curvam para atender aos mandos de sua consciência, construindo esta obra, se não a única, com certeza um ícone sobre o assunto.

Recebido em maio de 2004 Aprovado em junho de 2004

Sobre o autor:

Alexandre José Raad é psicólogo, mestrando do Programa de Pós-Graduação em Psicologia da Universidade São Francisco e professor nas Faculdades Módulo, da cidade de Caraguatatuba-SP. 